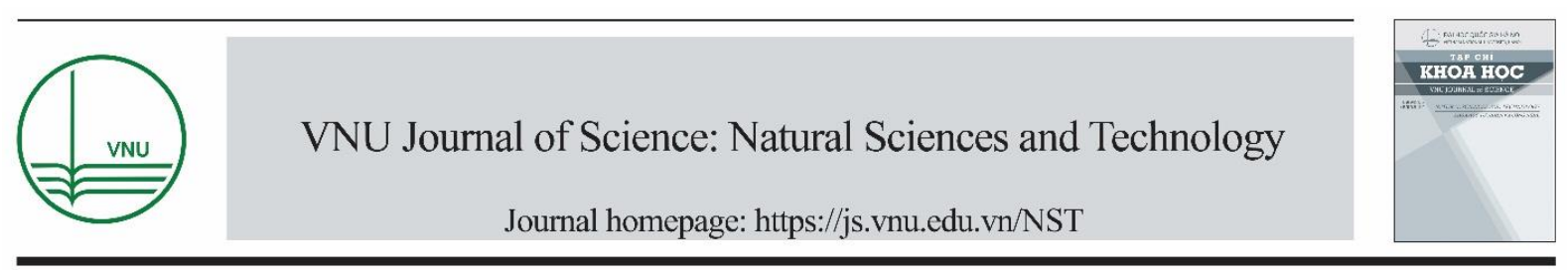

Original Article

\title{
Detection of Mitochondrial DNA Copy Number in Plasma Exosomes of Patients with Non-small Cell Lung Cancer
}

\author{
Le Thi Thanh Nhan ${ }^{1}$, Nguyen Thuy Quynh ${ }^{1}$, Le Lan Phuong ${ }^{1}$, Bui Phuong Thao ${ }^{1}$, \\ Nguyen Thi Tu Linh ${ }^{1}$, Le Trung Tho ${ }^{2}$, Trinh Hong Thai ${ }^{1, *}$ \\ ${ }^{I}$ VNU University of Science, 334 Nguyen Trai, Thanh Xuan, Hanoi, Vietnam \\ ${ }^{2}$ National Lung Hospital, 463 Hoang Hoa Tham, Ba Dinh, Hanoi, Vietnam
}

Received 21 October 2020

Revised 24 November 2020; Accepted 25 November 2020

\begin{abstract}
For the prevalence of lung cancer and its late- stage diagnosis, the seeking of the efficient biomarkers for this disease is an urgent requirement, especially from non-invasive samples such as plasma exosomes. The mitochondria DNA (mtDNA) copy number change has been evaluated as a potential indicator of cancer risk, however, there have been few studies regarding mtDNA in plasma derived exosomes. In this study, the mtDNA copy number was measured in 29 plasma exosome samples of patients with non-small cell lung cancer (NSCLC) and 29 plasma exosome samples of cancer-free controls by real-time PCR assay, then statistical analysis was performed to evaluate the relationship between mtDNA copy number in plasma exosomes and several pathological features of NSCLC. As the results, the existence of mtDNA in exosomes isolated from plasma was detected through PCR assay using primers covering most of the mtDNA length. The relative mtDNA copy numbers determined in the exosomes of the disease and control groups were $1619.1 \pm 2589.0$ and $1207.0 \pm 1550.0$, respectively, whereas these values in disease stages were $783.6 \pm 759.3$ (stage I-II) and $2647.0 \pm 3584.0$ (stage III-IV). Comparing among these groups, the difference was only statistically significant between the disease groups of stage I-II and stage III-IV $(p<0.05)$, the group of stage III-IV and the control group $(p<0.05)$. Indeed, the mtDNA copy number is associated with tumor stage and stage $\mathrm{N}(\mathrm{p}<0.05)$. On the other aspect, the smoking habit of NSCLC patients could be an underlying reason behind the alteration in mtDNA copy number in the plasma exosomes. In short, our study demonstrates that the mtDNA copy number in exosomes resourced from plasma could be a potential biomarker for NSCLC prognosis.
\end{abstract}

Keywords: mtDNA copy number, plasma exosome, non-small cell lung cancer, real-time PCR.

\footnotetext{
* Corresponding author.

E-mail address: thaith@vnu.edu.vn
}

https://doi.org/10.25073/2588-1140/vnunst.5150 


\title{
Xác định số bản sao DNA ty thể trong exosome huyết tương ở bệnh nhân ung thư phổi không tế bào nhỏ
}

\author{
Lê Thị Thanh Nhàn ${ }^{1}$, Nguyễn Thúy Quỳnh ${ }^{1}$, Lê Lan Phương ${ }^{1}$, Bùi Phương Thảo ${ }^{1}$, \\ Nguyễn Thị Tú Linh ${ }^{1}$, Lê Trung Thọ ${ }^{2}$ và Trịnh Hồng Thái ${ }^{1, *}$ \\ ${ }^{I}$ Trưòng Đại học Khoa học Tụ nhiên, ĐHQGHN, 334 Nguyễn Trãi, Thanh Xuân, Hà Nội, Việt Nam \\ ${ }^{2}$ Bệnh viện Phổi Trung ương, 463 Hoàng Hoa Thám, Ba Đình, Hà Nội, Việt Nam
}

Nhận ngày 21 tháng 10 năm 2020

Chỉnh sửa ngày 24 tháng 11 năm 2020; Chấp nhận đăng ngày 25 tháng 11 năm 2020

\begin{abstract}
Tóm tắt: Ung thư phổi là một trong những loại ung thư phổ biến hàng đầu trong các loại ung thư và thường được chẩn đoán ở giai đoạn muộn. Vì vậy, việc tìm kiếm chỉ thị sinh học của ung thư phổi là yêu cầu cấp thiết, đặc biệt là các chỉ thị sinh học trong mẫu không xâm lấn như exsome huyết tương. Sự thay đổi số bản sao DNA ty thể (mtDNA) được đánh giá là chỉ thị tiềm năng trong xác định nguy cơ ung thư. Tuy nhiên, cho đến nay vẫn còn ít nghiên cứu liên quan đến mtDNA trong exosome huyết tương. Trong nghiên cứu này, số bản sao mtDNA được xác định trên 29 mẫu exosome huyết tương của bệnh nhân ung thư phổi không tế bào nhỏ (UTPKTBN) và 29 mẫu exosome huyết tương đối chứng bằng phương pháp PCR định lượng, sau đó phân tích thống kê để đánh giá mối liên quan giữa số bản sao mtDNA trong exosome huyết tương với các đặc điểm bệnh học của UTPKTBN. Kết quả cho thấy đã xác định được sự có mặt của mtDNA trong exosome huyết tương thông qua các cặp mồi bao phủ phần lớn mtDNA. Số bản sao tương đối của mtDNA được xác định trong exosome của nhóm bệnh và nhóm đối chứng với giá trị tương ứng là $1619,1 \pm$ 2589,0 và $1207,0 \pm 1550,0$, trong đó giá trị theo giai đoạn bệnh là 783,6 4 759,3 (giai đoạn I-II) và $2647,0 \pm 3584,0$ (giai đoạn III-IV). So sánh giữa các nhóm với nhau, sự khác biệt chỉ có ý nghĩa thống kê giữa nhóm bệnh giai đoạn I-II với giai đoạn III-IV $(\mathrm{p}<0,05)$ và nhóm bệnh giai đoạn III-IV với nhóm đối chứng $(\mathrm{p}<0,05)$. Số bản sao mtDNA có liên quan đến giai đoạn bệnh và giai đoạn $\mathrm{N}(\mathrm{p}<0,05)$. Đặc biệt, nghiên cứu đã chỉ ra sự thay đổi số bản sao mtDNA trong exosome huyết tương có liên quan đến thói quen hút thuốc của bệnh nhân UTPKTBN. Kết quả nghiên cứu đã cho thấy số bản sao mtDNA trong exosome huyết tương có thể là chỉ thị tiềm năng trong đánh giá tiến triển của bệnh UTPKTBN.
\end{abstract}

Từ khóa: Số bản sao ADN ty thể, exosome huyết tương, ung thư phổi không tế bào nhỏ, PCR định lượng.

\section{Mở đầu}

Exosome là các bóng ngoại bào được chứng minh có ảnh hưởng đến nhiều quá trình sinh học liên quan đến khối u, đặc biệt, các DNA sợi kép được tìm thấy trong exosome có nguồn gốc khối u có thể đại diện cho hệ gen nhân và phản ánh tình trạng đột biến của các tế bào khối u $[1,2]$. Ngoài DNA trong nhân và DNA trong ty thể, tế bào cũng giải phóng exosome chứa

\footnotetext{
* Tác giả liên hệ.

Địa chỉ email: thaith@vnu.edu.vn

https://doi.org/10.25073/2588-1140/vnunst.5150
}

mtDNA đặc trưng cho loại tế bào tiết [3, 4]. Năm 2017, Sansone và cộng sự (cs) báo cáo rằng exosome có thể đóng gói và chuyển mtDNA vào các tế bào ung thư vú bị suy giảm về chuyển hóa, do đó khôi phục hoạt động trao đổi chất của chúng và dẫn đến kháng điều trị nội tiết [4]. Năm 2020, Li và cộng sự chứng minh rằng tình trạng bệnh ở gan (viêm gan và ung thư biểu mô tế bào gan) ảnh hưởng rõ rệt đến các đặc điểm của mtDNA trong các bóng ngoại bào, cho thấy giá trị ứng dụng lâm sàng tiềm năng của nó như một dấu ấn sinh học giúp chẩn đoán bổ sung cho mtDNA lưu hành [5]. Kết quả của các nghiên cứu nói trên cho thây 
rằng, mtDNA trong các bóng ngoại bào có thể là một dấu ấn mới giúp phát hiện ung thư. Tuy nhiên, cho đến nay, các đặc điểm của mtDNA trong bệnh nhân ung thư vẫn chưa được khám phá đầy đủ, điều này làm hạn chế đáng kể ứng dụng lâm sàng của mtDNA trong bệnh nhân ung thư.

Đối với mtDNA, số bản sao (SBS) mtDNA là yếu tố có ảnh hưởng đến sự hình thành và phát triển của ung thư [6]. SBS mtDNA, đặc biệt là mtDNA được đóng gói trong exosome đặc hiệu cho tế bào tiết có thể là một chỉ thị sinh học để phát hiện sớm và dự đoán tiên lượng bệnh. Vì vậy, trong nghiên cứu này, chúng tôi tiến hành xác định SBS mtDNA trong exosome huyết tương của bệnh nhân ung UTPKTBN nhằm đánh giá tình trạng mtDNA trong exosome làm cơ sở cho việc nghiên cứu ứng dụng chúng trong chẩn đoán và điều trị bệnh UTPKTBN ở Việt Nam.

\section{Vật liệu và phương pháp nghiên cứu}

\subsection{Vật liệu}

Mẫu nghiên cứu gồm 29 mẫu huyết tương của bệnh nhân UTPKTBN (16 mẫu của bệnh nhân ở giai đoạn I-II, 13 mẫu của bệnh nhân ở giai đoạn III-IV) do Bệnh viện Phổi Trung ương cung cấp. Mẫu đối chứng gồm 29 mẫu huyết tương được lấy từ người không mắc bệnh UTPKTBN do bệnh viện Đại học Quốc gia Hà Nội và Bệnh viện Xanh-Pon cung cấp.

Việc lấy mẫu được thực hiện theo các quy định hiện hành về đạo đức trong nghiên cứu $\mathrm{y}$ học. Mẫu có các thông tin của bệnh nhân như tuổi, giới tính, thói quen hút thuốc, tiền sử uống rượu, giai đoạn bệnh và phân giai đoạn phát triển của $\mathrm{u}(\mathrm{TNM})$ với sự chấp thuận tự nguyện cho mẫu từ bệnh nhân và người nhà bệnh nhân (được thể hiện trong bản cam kết chấp nhận cho mẫu). Mặt khác, mẫu chỉ được sử dụng cho nghiên cứu và không được sử dụng cho mục đích khác.

\subsection{Phưong pháp}

Phân tách exosome tù huyết tuoong: $300 \mu 1$ mẫu huyết tương của mỗi bệnh nhân được ly tâm 10.000 vòng/phút trong 5 phút ở $4{ }^{\circ} \mathrm{C}$, tiếp theo huyết tương được bổ sung $300 \mu \mathrm{l}$ đệm PBS pH 7,4 (đệm đã được lọc qua màng lọc $0,22 \mu \mathrm{m})$, sau đó dịch lọc được siêu ly tâm 60.000 vòng/phút ở $4{ }^{\circ} \mathrm{C}$ trong 70 phút sử dụng rotor góc cố định MLA-130 (Beckman Coulter, Mỹ), thu cặn exosome. Cặn được hòa tan với $300 \mu 1$ đệm PBS pH 7,4. Dung dịch được siêu ly tâm lần 2 với 60.000 vòng/phút ở $4{ }^{\circ} \mathrm{C}$ trong 70 phút, loại bỏ dịch nổi, thu cặn exosome cho các bước nghiên cứu tiếp theo.

Xủ lý với dsDNase: cặn chứa exosome được xử lý với enzyme dsDNase (Thermo Scientific, Mỹ), ủ ơ $37^{\circ} \mathrm{C}$ trong 5 phút và bất hoạt enzyme ở $55{ }^{\circ} \mathrm{C}$ trong 5 phút trước khi tiến hành tách DNA tổng số.

Tách chiết DNA tổng số: DNA tổng số trong exosome được tách chiết bằng QIAamp DNA mini kit (QIAGEN, Đức) theo hướng dẫn của nhà sản xuất, mẫu sau tách được cô đặc bằng máy cô chân không (Speedvac - Thermo Scientific, Mỹ) từ thể tích $200 \mu \mathrm{l}$ xuống còn $20 \mu$ l. Nồng độ DNA tổng số sau tách được định lượng bằng đo mật độ hấp thụ ánh sáng tử ngoại của acid nucleic ở bước sóng $260 \mathrm{~nm}$ ( $\mathrm{A}_{260}$ ) sử dụng máy NanoDrop 2000c (Thermo Scientific, Mỹ). Độ tinh sạch của DNA tách chiết được xác định bằng tỷ số $\mathrm{A}_{260} / \mathrm{A}_{280}$ trong khoảng 1,8-2,0. DNA tổng số được bảo quản ở $-20^{\circ} \mathrm{C}$ cho đến khi sử dụng.

Xác nhận sự có mặt của mtDNA trong DNA tổng số: phản ứng PCR được thực hiện với 13 cặp mồi được thiết kế nhằm bắt cặp với các vị trí cụ thể trên mtDNA (Bảng 1). Chu trình nhiệt được sử dụng nhân các đoạn gen như sau: $94{ }^{\circ} \mathrm{C}, 5$ phút; 35 chu kỳ $\left(94{ }^{\circ} \mathrm{C}, 20\right.$ giây; $56^{\circ} \mathrm{C}$, 30 giây; $72{ }^{\circ} \mathrm{C}, 45$ giây); $72{ }^{\circ} \mathrm{C}, 5$ phút. Sau đó, sản phẩm $\mathrm{PCR}$ được trộn với dye Runsafe (Cleaver Scientific, Anh) và điện di kiểm tra trên gel agarose $1,5 \%$. Hình ảnh bản gel điện di được quan sát trên máy soi gel điện di và chụp ảnh trên máy Chemidoc (Bio-Rad, Mỹ).

Xác định số bản sao mtDNA: thực hiện phản ứng PCR định lượng (qPCR) với hai cặp mồi ND1-2 (kích thước sản phẩm 115 bp) và HBB (kích thước sản phẩm 104 bp) được thiết 
kế để nhân lần lượt các đoạn DNA của gen $N D 1$ nằm trong vùng ít xảy ra mất đoạn (đại diện cho DNA ty thể) và gen $H B B$ (Hemoglobin subunit beta) đại diện cho DNA nhân. Quá trình khuếch đại sử dụng $\mathrm{iTaq}^{\mathrm{TM}}$ Universal SYBR ® Green Super mix (Bio-Rad, Mỹ) theo hướng dẫn của nhà sản xuất với thành phần khuôn DNA tổng số của mẫu exosome là $2 \mu 1$. Mẫu DNA tổng số được pha loãng với 3 nồng độ khác nhau và thực hiện phân tích trên máy realtime PCR 7500 fast với chu trình nhiệt như sau: $95^{\circ} \mathrm{C}, 2$ phút; 40 chu kỳ $\left(95^{\circ} \mathrm{C}, 15\right.$ giây; $58{ }^{\circ} \mathrm{C}, 30$ giây); $95^{\circ} \mathrm{C}, 15$ giây.

Cường độ tín hiệu huỳnh quang được ghi nhận sau khi kết thúc một chu kỳ và được phân tích bằng phần mềm 7500 software v2.3. Giá trị chu kỳ ngưỡng $(\mathrm{Ct})$ thu được của mẫu nghiên cứu được sử dụng để tính toán SBS tương đối của $\mathrm{ADN}$ ty thể $=2^{-\Delta \mathrm{Ct}}\left(\Delta \mathrm{C}_{\mathrm{t}}=\mathrm{C}_{\mathrm{t}} N D 1-\mathrm{C}_{\mathrm{t}} H B B\right)$ [7].

Bảng 1.13 cặp mồi mtDNA sử dụng cho PCR

\begin{tabular}{|l|l|l|l|}
\hline Cặp mồi & Tên mồi & Trình tự mồi (5'-3') & Kích thước sản phẩm (bp) \\
\hline $13 \mathrm{mt}-01$ & $\begin{array}{l}522 \mathrm{~F} \\
1032 \mathrm{R}\end{array}$ & $\begin{array}{l}\text { CACCGCTGCTAACCCCATA } \\
\text { GCCACTTTCGTAGTCTATTTTGT }\end{array}$ & 511 \\
\hline $13 \mathrm{mt}-02$ & $\begin{array}{l}1022 \mathrm{~F} \\
1715 \mathrm{R}\end{array}$ & $\begin{array}{l}\text { ACGAAAGTGGCTTTAACATATCTG } \\
\text { GGTTGCTGGTAGTAAGGTGGAG }\end{array}$ & 694 \\
\hline $13 \mathrm{mt}-03$ & $\begin{array}{l}3119 \mathrm{~F} \\
3894 \mathrm{R}\end{array}$ & $\begin{array}{l}\text { CCCTGTACGAAAGGACAAGAG } \\
\text { GGTTCGGTTGGTCTCTGCT }\end{array}$ & 776 \\
\hline $13 \mathrm{mt}-04$ & $\begin{array}{l}3706 \mathrm{~F} \\
4467 \mathrm{R}\end{array}$ & $\begin{array}{l}\text { CGAGCAGTAGCCCAAACAATC } \\
\text { GTACGGGAAGGGTATAACCAACA }\end{array}$ & 762 \\
\hline $13 \mathrm{mt}-05$ & $\begin{array}{l}5301 \mathrm{~F} \\
5972 \mathrm{R}\end{array}$ & $\begin{array}{l}\text { ATCCCCACCATCATAGCCAC } \\
\text { GCCGAATAATAGGTATAGTGTTCCA }\end{array}$ & 672 \\
\hline $13 \mathrm{mt}-06$ & $\begin{array}{l}7066 \mathrm{~F} \\
7726 \mathrm{R}\end{array}$ & $\begin{array}{l}\text { CCATCATAGGAGGCTTCATTCAC } \\
\text { TGTGAGTGTTAGGAAAAGGGCA }\end{array}$ & 661 \\
\hline $13 \mathrm{mt}-07$ & $\begin{array}{l}8187 \mathrm{~F} \\
8872 \mathrm{R}\end{array}$ & $\begin{array}{l}\text { CGTCTAAACCAAACCACTTTCACC } \\
\text { CTATAATCACTGTGCCCGCTCA }\end{array}$ & 756 \\
\hline $13 \mathrm{mt}-08$ & $\begin{array}{l}8631 \mathrm{~F} \\
9333 \mathrm{R}\end{array}$ & $\begin{array}{l}\text { ATATCTCATCAACAACCGACTAATC } \\
\text { GGAGCGTTATGGAGTGGAAG }\end{array}$ & 703 \\
\hline $13 \mathrm{mt}-09$ & $\begin{array}{l}9927 \mathrm{~F} \\
10816 \mathrm{R}\end{array}$ & $\begin{array}{l}\text { TACTGGCATTTTGTAGATGTGGTT } \\
\text { TTTGGAAAGTCATGTCAGTGGTAG }\end{array}$ & 890 \\
\hline $13 \mathrm{mt}-10$ & $\begin{array}{l}11977 \mathrm{~F} \\
12916 \mathrm{R}\end{array}$ & $\begin{array}{l}\text { CTCCCTCTACATATTTACCACAACA } \\
\text { TGGAGTGTAGGATAAATCATGCTAA }\end{array}$ & 940 \\
\hline $13 \mathrm{mt}-11$ & $\begin{array}{l}11578 \mathrm{~F} \\
12476 \mathrm{R}\end{array}$ & $\begin{array}{l}\text { CTCCATCTGCCTACGACAAAC } \\
\text { CTGATAATAAAGGTGGATGCGAC }\end{array}$ & 899 \\
\hline $13 \mathrm{mt}-12$ & $\begin{array}{l}12823 \mathrm{~F} \\
13652 \mathrm{R}\end{array}$ & $\begin{array}{l}\text { GATGCCAACACAGCAGCC } \\
\text { GTGGGGAAGCGAGGTTGA }\end{array}$ & 830 \\
\hline $13 \mathrm{mt}-13$ & $\begin{array}{l}14358 \mathrm{~F} \\
14989 \mathrm{R}\end{array}$ & $\begin{array}{l}\text { CCCACAGCACCAATCCTACC } \\
\text { GTAGCGGATGATTCAGCCATAA }\end{array}$ & 632 \\
\hline
\end{tabular}

Phân tích thống kê: phần mềm Excel 2010, phần mềm SPSS 23 và phần mềm GraphPad Prism 8.4.2 được sử dụng để vẽ hình và phân tích số liệu theo các kiểm định thống kê thường dùng. Số liệu được biểu diễn bằng số trung bình và độ lệch chuẩn. Kiểm định thống kê sử dụng Mann-Whitney U test và được ghi nhận theo hai chiều với giá trị $\mathrm{p}<0,05$ được coi là có ý nghĩa thống kê.

\section{Kết quả và thảo luận}

3.1. Xác nhận sự có mặt của DNA ty thể trong DNA tổng số được tách tù exosome

Trước khi tách DNA tổng số từ exosome, mẫu exosome đã được xử lý với dsDNAse để loại bỏ DNA bên ngoài exosome. Sự có mặt của mtDNA trong mẫu DNA tổng số được xác định bằng 13 cặp mồi bắt cặp đặc hiệu với các vị trí của mtDNA thông qua phản ứng PCR. Kết quả 
điện di sản phẩm PCR (Hình 1) cho thấy đã thu được đủ 13 băng tương ứng với 13 cặp mồi và tất cả chúng đều có kích thước tương ứng theo tính toán lý thuyết (Bảng 1). Các băng sáng, rõ nét và không xuất hiện băng phụ chứng tỏ đã thu được sản phẩm PCR đặc hiệu, cho thấy sự có mặt của mtDNA trong DNA tổng số tách được từ exosome huyết tương.

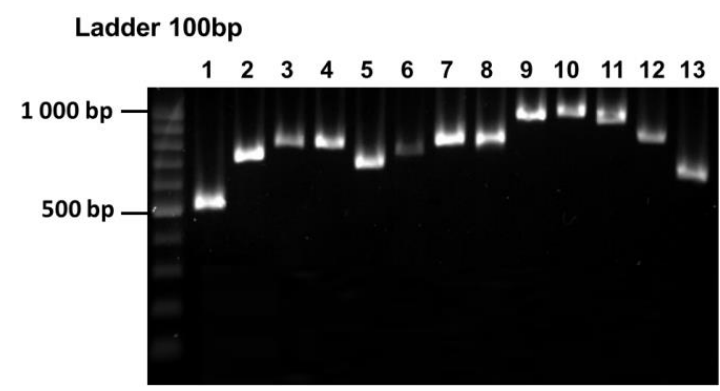

Hình 1. Ảnh điện di sản phẩm PCR sử dụng 13 cặp mồi trên gel agarose $1,5 \%$.

Ghi chú: Thứ tự các giếng là thứ tự các cặp mồi 1-13, khuôn là DNA tổng số trong exosome huyết tương.

Một số nghiên cứu cũng đã xác nhận sự có mặt của mtDNA tách từ exosome thông qua các cặp mồi đặc hiệu. Sử dụng cả phương pháp PCR đoạn dài và 46 cặp mồi đặc hiệu, Sansone và cộng sự [4] đã xác định được toàn bộ hệ gen ty thể có trong exosome huyết tương từ bệnh nhân ung thư vú kháng trị liệu hormone [4]. Hệ gen ty thể cũng đã được xác định trong bóng ngoại bào được tách từ huyết tương của bệnh nhân ung thư gan bằng phương pháp giải trình tự thế hệ mới [5]. Như vậy, nghiên cứu của chúng tôi đã cung cấp thêm bằng chứng về sự có mặt của mtDNA trong exosome huyết tương.

\subsection{Số bản sao mtDNA trong exosome huyết tuoong}

SBS mtDNA được xác định dựa trên phản ứng qPCR sử dụng 2 cặp mồi tương ứng với gen $N D 1$ ty thể nằm trong vùng ít xảy ra mất đoạn (có mặt trong khoảng 94\% các trường hợp mất đoạn đơn và $100 \%$ các trường hợp có nhiều mất đoạn cùng lúc) và gen nhân $H B B$ [8].

Trong $\mathrm{qPCR}$, đường cong nóng chảy giúp đánh giá tính đặc hiệu của phản ứng dựa vào số đỉnh và hình dạng đỉnh của các đường biểu diễn nhiệt độ nóng chảy. Phân tích kết quả thu được cho thấy phản ứng qPCR không có sản phẩm phụ với nhiệt độ nóng chảy của các gen $N D 1$ và $H B B$ tương ứng là $80,48{ }^{\circ} \mathrm{C}$ và $84,04{ }^{\circ} \mathrm{C}$ (Hình $2 \mathrm{~A}$ ). Bên cạnh đó, kết quả điện di các sản phẩm qPCR trên gel agarose $2 \%$ thu được các băng sáng, rõ nét, không xuất hiện băng phụ (Hình 2B), chứng minh các cặp mồi đã nhân bản đặc hiệu các gen quan tâm và có thể được sử dụng để định lượng.

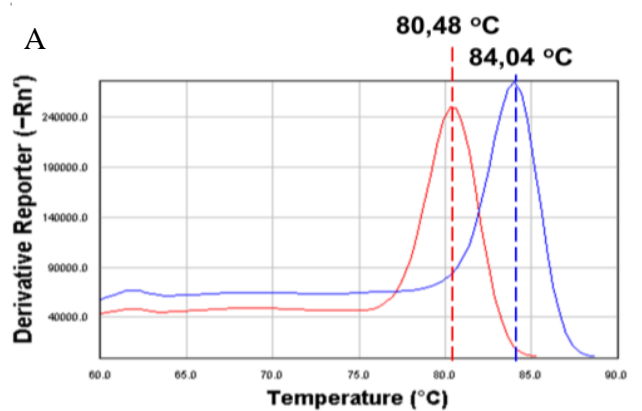

B

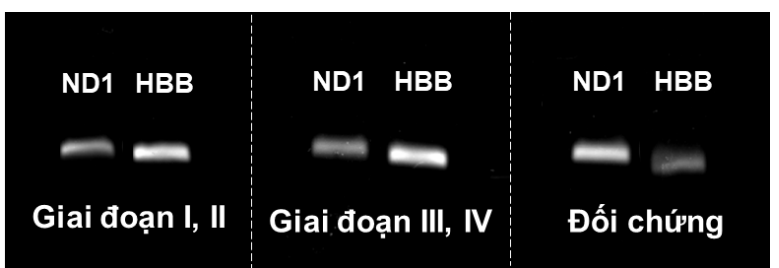

Hình 2. Đường cong nóng chảy và nhiệt độ nóng chảy qPCR của các gen ND1 và HBB (A)

Các băng sản phẩm qPCR tương ứng trong bản gel điện di agarose $2 \%(\mathrm{~B})$.

Số bản sao tương đối mtDNA trong exosome huyết tương được thể hiện bằng giá trị trung bình và độ lệch chuẩn $(\mathrm{TB} \pm \mathrm{OLC})$ với giá trị tương ứng là 783,6 \pm 759,3 (nhóm bệnh giai đoạn I-II), 2647,0 \pm 3584,0 (nhóm bệnh giai đoạn III-IV) và $1207,0 \pm 1550,0$ (nhóm đối chứng). So sánh giữa các nhóm với nhau, sự khác biệt chỉ có ý nghĩa thống kê giữa nhóm bệnh giai đoạn I-II với giai đoạn III-IV $(\mathrm{p}<0,05)$ và nhóm bệnh giai đoạn III-IV với nhóm đối chứng $(\mathrm{p}<0,05)$ (Hình 3 ). Kết quả phân tích liên quan trong Bảng 2 cho thấy SBS mtDNA có liên quan đển giai đoạn bệnh, thói quen hút thuốc và giai đoạn $\mathrm{N}(\mathrm{p}<0,05)$. 


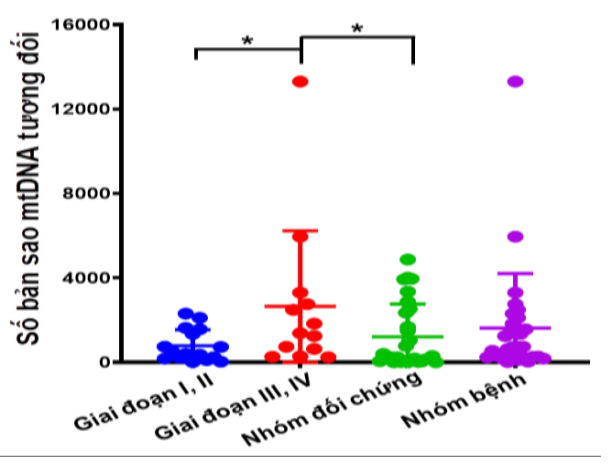

Hình 3. Số bản sao mtDNA trong exosome huyết tương giữa các nhóm.

Ghi chú: Mỗi dấu • thể hiện cho từng trường hợp. Các đường nằm ngang thể hiện giá trị $\mathrm{TB} \pm \mathrm{ĐLC}$. $*: \mathrm{p}<0,05$.

Bảng 2. Mối liên quan giữa số bản sao tương đối của mtDNA trong exosome huyết tương và các đặc điểm của bệnh nhân

\begin{tabular}{|c|c|c|c|c|}
\hline \multicolumn{2}{|c|}{ Đặc điểm } & \multirow{3}{*}{$\begin{array}{c}\text { Số bệnh nhân (n) } \\
12 \\
\end{array}$} & \multicolumn{2}{|c|}{ Số bản sao tương đối mtDNA } \\
\hline & & & $\mathrm{TB} \pm \mathrm{ĐLC}$ & $\mathrm{P}^{\mathrm{a}}$ \\
\hline \multirow[t]{2}{*}{ Tuổi (năm) } & $\leq 60$ & & $1038,0 \pm 1064,0$ & 0,29 \\
\hline & $>60$ & 17 & $2442,0 \pm 3762,0$ & \\
\hline \multirow[t]{2}{*}{ Giới tính } & Nam & 15 & $1976,0 \pm 3474,0$ & 0,86 \\
\hline & Nữ & 14 & $1237,0 \pm 1067,0$ & \\
\hline \multirow[t]{2}{*}{ Hút thuốc } & Có & 12 & $742,6 \pm 810,6$ & 0,04 \\
\hline & Không & 17 & $2238,0 \pm 3209,0$ & \\
\hline \multirow[t]{2}{*}{ Uống rượu } & Có & 10 & $1964,0 \pm 4041,0$ & 0,38 \\
\hline & Không & 19 & $1437,0 \pm 1470,0$ & \\
\hline \multirow[t]{2}{*}{ Kích thước u } & $0-3 \mathrm{~cm}$ & 13 & $830,0 \pm 859,6$ & 0,11 \\
\hline & $>3 \mathrm{~cm}$ & 15 & $2375,0 \pm 3391,0$ & \\
\hline \multirow[t]{2}{*}{ Giai đoạn bệnh } & I-II & 16 & $783,6 \pm 759,3$ & 0,04 \\
\hline & III-IV & 13 & $2647,0 \pm 3584,0$ & \\
\hline \multirow[t]{2}{*}{ Giai đoạn T } & T1-T2 & 14 & $868,9 \pm 773,2$ & 0,22 \\
\hline & T3-T4 & 15 & $2319,0 \pm 3430,0$ & \\
\hline \multirow[t]{2}{*}{ Giai đoạn N } & No & 14 & $770,8 \pm 793,7$ & 0,04 \\
\hline & $\mathrm{N} 1-3$ & 15 & $2411,0 \pm 3381,0$ & \\
\hline \multirow[t]{2}{*}{ Giai đoạn M } & M0 & 20 & $1021,0 \pm 977,4$ & 0,22 \\
\hline & M1 & 9 & $2948,0 \pm 4279,0$ & \\
\hline \multicolumn{5}{|c|}{ Ghi chú: ${ }^{\text {a }}$ Mann-Whitney U test. } \\
\hline
\end{tabular}

Các kết quả trên đã cho thấy số bản sao mtDNA trong exosome huyết tương có liên quan đến bệnh UTPKTBN. Gần đây, mối liên quan giữa thay đổi $S B S$ mtDNA và bệnh ung thư đã được báo cáo trong một số nghiên cứu. Sử dụng mẫu phân tích là bạch cầu máu ngoại vi của nhóm bệnh nhân ung thư và nhóm đối chứng khỏe mạnh, SBS mtDNA ở nhóm bệnh được tìm thấy cao hơn có ý nghĩa thống kê so với nhóm đối chứng đối với bệnh ung thư dạ dày [9], ung thư đầu và cổ [10]. Các nghiên cứu đều cho thây SBS mtDNA cao có liên quan đến nguy cơ của bệnh ung thư dạ dày [9], ung thư đầu và cổ [10] và ung thư phổi [11]. Tuy nhiên, 
trên mẫu exosome hoặc bóng tiết ngoại bào (EV) được tách từ huyết tương, kết quả xác định SBS mtDNA cho thấy sự khác biệt theo loại ung thư, SBS tăng trong ung thư buồng trứng [12] và giảm trong ung thư tế bào gan [5]. Đáng chú ý đối với ung thư buồng trứng, SBS mtDNA đã được xác định đồng thời trong 3 loại mẫu (DNA exosome huyết tương, DNA lưu hành trong máu và $\mathrm{DNA}$ máu toàn phần), trong đó SBS mtDNA cao nhất thuộc về DNA exosome [12]; tuy nhiên, với ung thư gan, SBS mtDNA trong DNA exosme huyết tương không thuộc loại cao nhất [5].

Mặc dù, dữ liệu của chúng tôi không chỉ ra sự khác biệt có ý nghĩa giữa SBS mtDNA trong exosome huyết tương ở nhóm bệnh nhân UTPKTBN so với đối chứng $(\mathrm{p}=0,19)$, tuy nhiên ở cả nghiên cứu của chúng tôi và Keserủ đều cho thấy SBS mtDNA tăng rõ rệt ở giai đoạn III-IV so với giai đoạn sớm và nhóm đối chứng (giá trị $\mathrm{p}=0,04$ và $\mathrm{p}=0,0095$ tương ứng) [12]. Hơn nữa, kết quả phân tích còn cho thấy SBS mtDNA có liên quan đến thói quen hút thuốc của bệnh nhân UTPKTBN. Điều này cũng đã được tìm thấy trong nghiên cứu đối với bệnh ung thư phổi $[11,13]$ và $\mathrm{SBS}$ mtDNA tăng cao dẫn đến nguy cơ cao ung thư phổi, nhất là nhóm bệnh nhân có thói quen hút thuốc.

Tóm lại, chúng tôi quan sát thấy rằng thay đổi SBS mtDNA trong exosome huyết tương có thể là dấu hiệu tiến triển của bệnh UTPKTBN. Nhưng vì số lượng mẫu trong nghiên cứu này còn ít nên việc đánh giá tiềm năng của mtDNA trong exosome huyết tương còn bị hạn chế. Do đó, việc xác định SBS mtDNA trong exosome huyết tương ở bệnh nhân UTPKTBN với số lượng mẫu lớn hơn là điều cần thiết.

\section{Kết luận}

Số bản sao DNA ty thể trong exosome huyết tương tăng ở giai đoạn muộn của bệnh đã cho thấy vai trò tiềm năng của chúng ứng dụng làm chỉ thị trong đánh giá tiến triển đối với bệnh ung thư phổi không tế bào nhỏ. Số bản sao mtDNA có liên quan với giai đoạn $\mathrm{N}$ và thói quen hút thuốc của bệnh nhân nhưng không có liên quan với tuổi, giới tính, kích thước khối u, giai đoạn $\mathrm{T}$, giai đoạn $\mathrm{M}$ và thói quen uống rượu của bệnh nhân.

\section{Lời cảm ơn}

Nhóm tác giả xin chân thành cảm ơn các bệnh nhân đã tự nguyên cho mẫu nghiên cứu, các $\mathrm{y}$ bác sĩ của Bệnh viện Phổi Trung ương, Bệnh viện Đại học Quốc gia và Bệnh viện Xanh-pon đã hỗ trợ lấy mẫu. Nghiên cứu này được hỗ trợ kinh phí từ đề tài KLEPT.18.03, Đại học Quốc Gia Hà Nội.

\section{Tài liệu tham khảo}

[1] Y. Shao, Y. Shen, T. Chen, F. Xu, X. Chen, S. Zheng, The Functions and Clinical Applications of Tumor-derived Exosomes, Oncotarget, Vol. 7, No. 37, 2016, pp. 60736-60751, https://doi.org/10.18632/oncotarget.11177.

[2] B. K. Thakur, H. Zhang, A. Becker, I. Matei, Y. Huang, B. C. Silva, Y. Zheng, A. Hoshino, H. Brazier, J. Xiang, C. Williams, R. R. Barrueco, J. M. Silva, W. Zhang, S. Hearn, O. Elemento, N. Paknejad, K. M. Todorova, K. Welte, J. Bromberg, H. Peinado, D. Lyden, Double-stranded DNA in Exosomes: A Novel Biomarker in Cancer Detection, Cell Res, Vol. 24, No. 6, 2014, pp. 766-769, https://doi.org/10.1038/cr.2014.44.

[3] J. V. Philley, A. Kannan, W. Qin, E. R. Sauter, M. Ikebe, K. L. Hertweck, D. A. Troyer, O. J. Semmes, S. Dasgupta, Complex-I Alteration and Enhanced Mitochondrial Fusion are Associated with Prostate Cancer Progression, J. Cell Physiol, Vol. 231, No. 6, 2016, pp. 1364-1374, https://doi.org/10.1002/jcp.25240.

[4] P. Sansone, C. Savini, I. Kurelac, Q. Chang, L. B. Amato, A. Strillacci, A. Stepanova, L. Iommarini, C. Mastroleo, L. Daly, A. Galkin, B. K. Thakur, N. Soplop, K. Uryu, A. Hoshino, L. Norton, M. Bonafé, M. Cricca, G. Gasparre, D. Lyden, J. Bromberg, Packaging and Transfer of Mitochondrial DNA Via Exosomes Regulate Escape from Dormancy in Hormonal Therapy-resistant Breast Cancer, Proc Natl Acad Sci USA, Vol. 114, No. 43, 2017, pp. E9066-E9075, https://doi.org/10.1073/pnas.1704862114.

[5] Y. Li, X. Guo, S. Guo, Y. Wang, L. Chen, Y. Liu, M. Jia, J. An, K. Tao, J. Xing, Next Generation Sequencing-based Analysis of Mitochondrial DNA Characteristics in Plasma Extracellular Vesicles of 
Patients with Hepatocellular Carcinoma, Oncol Lett, Vol. 20, No. 3, 2020, pp. 2820-2828, https://doi.org/10.3892/ol.2020.11831.

[6] E. Reznik, M. L. Miller, Y. Şenbabaoğlu, N. Riaz, J. Sarungbam, S. K. Tickoo, H. A. A. Ahmadie, W. Lee, V. E. Seshan, A. A. Hakimi, C. Sander, Mitochondrial DNA Copy Number Variation Across Human Cancers, ELife, Vol. 5, 2016, pp. 1-20, https://doi.org/10.7554/eLife.10769.

[7] K. J. Livak, T. D. Schmittgen, Analysis of Relative Gene Expression Data using Real-time Quantitative PCR and the $2^{-\Delta \Delta C t}$ Method, Methods, Vol. 25, No. 4 , 2001, pp. 402-408, https://doi.org/10.1006/meth.2001.1262.

[8] MITOMAP: A Human Mitochondrial Genome Database Center for Molecular Medicine, Emory University, Atlanta, GA, USA,

http://www.gen.emory.edu/mitomap.html/, 2020 (accessed on: September 20 $0^{\text {th }}, 2020$ ).

[9] J. Fernandes, V. Michel, M. C. Ponce, A. Gomez, C. Maldonado, H. De Reuse, J. Torres, E. Touati, Circulating Mitochondrial DNA Level, a Noninvasive Biomarker for the Early Detection of Gastric Cancer, Cancer Epidemiol Biomarkers Prev, Vol. 23, No. 11, 2014, pp. 2430-2438, https://doi.org/10.1158/1055-9965.EPI-14-0471.
[10] L. Wang, H. Lv, P. Ji, X. Zhu, H. Yuan, G. Jin, J. Dai, Z. Hu, Y. Su, H. Ma, Mitochondrial DNA Copy Number is Associated with Risk of Head and Neck Squamous Cell Carcinoma in Chinese Population, Cancer Med, Vol. 7, No. 6, 2018, pp. 2776-2782, https://doi.org/10.1002/cam4.1452.

[11] H. D. Hosgood III, C. S. Liu, N. Rothman, S. J. Weinstein, M. R. Bonner, M. Shen, U. Lim, J. Virtamo, W. L. Cheng, D. Albanes, Q. Lan, Mitochondrial DNA Copy Number and Lung Cancer Risk in a Prospective Cohort Study, Carcinogenesis, Vol. 31, No. 5, 2010, pp. 847-849, https://doi.org/10.1093/carcin/bgq045.

[12] J. S. Keserü, B. Soltész, J. Lukács, É. Márton, M. S. Bónizs, A. Penyige, R. Póka, B. Nagy, Detection of Cell-free, Exosomal and Whole Blood Mitochondrial DNA Copy Number in Plasma or Whole Blood of Patients with Serous Epithelial Ovarian Cancer, J. Biotechnol, Vol. 298, 2019, pp. 76-81, https://doi.org/10.1016/j.jbiotec.2019.04.015.

[13] S. Meng, I. De Vivo, L. Liang, Z. Hu, D. C. Christiani, E. Giovannucci, J. Han, Pre-diagnostic Leukocyte Mitochondrial DNA Copy Number and Risk of Lung Cancer, Oncotarget, Vol. 7, No. 19, 2016, pp. 27307-27312, https://doi.org/10.18632/oncotarget.8426. 